\title{
BMJ Open Healthcare experiences of patients with chronic heart failure in Germany: a scoping review
}

\author{
Mirjam Dieckelmann, ${ }^{1}$ Juliana J Petersen, ${ }^{1}$ Corina Güthlin, ${ }^{1}$ Felix Reinhardt, ${ }^{1}$ \\ Jasper Plath, ${ }^{1}$ Klaus Jeitler, ${ }^{2,3}$ Thomas Semlitsch, ${ }^{2}$ Ferdinand M Gerlach, ${ }^{1}$ \\ Andrea Siebenhofer (iD) ${ }^{1,3}$
}

To cite: Dieckelmann M, Petersen JJ, Güthlin C, et al. Healthcare experiences of patients with chronic heart failure in Germany: a scoping review. BMJ Open 2020;10:e037158. doi:10.1136/ bmjopen-2020-037158

- Prepublication history for this paper is available online. To view these files, please visit the journal online (http://dx.doi. org/10.1136/bmjopen-2020037158).

Received 22 January 2020 Revised 05 May 2020 Accepted 21 July 2020

Check for updates

(C) Author(s) (or their employer(s)) 2020. Re-use permitted under CC BY-NC. No commercial re-use. See rights and permissions. Published by BMJ.

${ }^{1}$ Institute of General Practice, Goethe University Frankfurt, Frankfurt am Main, Germany ${ }^{2}$ Institute of General Practice and Evidence-based Health Services Research, Medical University of Graz, Graz, Austria

Institute for Medical Informatics, Statistics and Documentation, Medical University of Graz, Graz, Austria

Correspondence to Professor Andrea Siebenhofer; andrea.siebenhofer@ medunigraz.at

\section{ABSTRACT}

Objectives To review systematically the past 10 years of research activity into the healthcare experiences (HCX) of patients with chronic heart failure (CHF) in Germany, in order to identify research foci and gaps and make recommendations for future research.

Design In this scoping review, six databases and grey literature sources were systematically searched for articles reporting $\mathrm{HCX}$ of patients with $\mathrm{CHF}$ in Germany that were published between 2008 and 2018. Extracted results were summarised using quantitative and qualitative descriptive analysis.

Results Of the 18 studies (100\%) that met the inclusion criteria, most were observational studies $(60 \%)$ that evaluated findings quantitatively $(60 \%)$. HCX were often concerned with patient information, global satisfaction as well as relationships and communication between patients and providers and generally covered ambulatory care, hospital care and rehabilitation services. Overall, the considerable heterogeneity of the included studies' outcomes only permitted relatively trivial levels of synthesis.

Conclusion In Germany, research on HCX of patients with $\mathrm{CHF}$ is characterised by missing, inadequate and insufficient information. Future research would benefit from qualitative analyses, evidence syntheses, longitudinal analyses that investigate $\mathrm{HCX}$ throughout the disease trajectory, and better reporting of sociodemographic data. Furthermore, research should include studies that are based on digital data, reports of experiences gained in under-investigated yet patient-relevant healthcare settings and include more female subjects.

\section{INTRODUCTION}

Patients with chronic heart failure (CHF) have to cope with immense workloads. They may view both their disease(s) and their treatment as a burden when engaging in self-care and seeking help from a range of healthcare providers and services. To manage their condition, patients and their social networks are required to make lifestyle changes, to know when and how to seek help in acute situations and to initiate contact with and choosing between providers of long-term

\section{Strengths and limitations of this study}

By systematically mapping the research field around healthcare experience of patients with chronic heart failure, we find that, for Germany, research is characterised by missing, insufficient and inadequate information.

- We were able to infer targeted recommendations for future primary research on healthcare experiences in patients with chronic heart failure and encourage replication of the fully published searches for contexts other than Germany.

- This review includes both, grey literature sources and published research articles detected through searching multiple electronic databases.

- As of yet, heterogeneous outcomes of healthcare experiences in the included studies allow only for relatively trivial levels of synthesis.

- Although a patient representative was involved, integrating the patient perspective further in the review process could have helped to understand which research gaps were most relevant to the patient and should be given priority in future research.

psychosocial, mental and physical support. They also commonly face tasks such as doing paperwork and communicating with funding bodies, becoming tech-savvy or comprehending complex medical information and its multitude of sources. ${ }^{1}$

Burden of treatment as well as minimally disruptive medicine are concepts that have gained research momentum in the past decade.$^{2-7}$ Perceived treatment burden negatively impacts on adherence, damage the health of patients and their families reduce employment among chronically ill patients and hinder effective resource use. ${ }^{68}$ A recently developed situation-specific theory of selfcare in heart failure suggests that past experiences influence decision-making processes with respect to a patient's ability to care for himself or herself. Importantly, experiences 
in healthcare settings may act as both, barriers and facilitators and thus influence self-care behaviours and selfefficacy in positive and negative ways. ${ }^{8}$

The literature suggests that 'treatment burden is concerned with the negative experiences resulting from the process of undertaking treatment' ${ }^{9}$ We have, however, chosen to use the more neutral term, patient healthcare experiences (HCX). HCX 'consists of the multitudinous interactions originating at the interface between disease-specific, subjective healthcare needs and the healthcare services used by patients. They encompass various dimensions-whether they be relational, organisational or functional in nature-either obtained from the patients themselves, or otherwise accurately reflecting the patient's views'. ${ }^{10}$ This working definition shifts the focus from an investigation of experiences of self-care and monitoring tasks towards examining experiences concerned with help-seeking and, more specifically, encounters with the healthcare system.

Investigating encounters between patients and healthcare systems, especially from the point of view of patients with multimorbidity, has received much attention in the USA and the UK. ${ }^{11}$ Nevertheless, little is known about the subjective HCX of patients with CHF that are specifically confronted with the complex German healthcare infrastructure.

The scoping review methodology is particularly wellsuited to broad research concepts. ${ }^{12-14}$ Correspondingly, HCX as a concept of interest has not yet been uniformly defined in the literature, and we anticipated that evidence would be many-sided and based on diverse research areas. Unlike qualitative evidence syntheses, a scoping review's focus rather is on mapping the presence and extent of available research and can therefore act as a precursor to full systematic reviews. ${ }^{14}$

This scoping review is the first in Germany to systematically investigate research into HCX of patients with CHF, with the aim of developing recommendations for targeted future research in the field. Specifically, it seeks to summarise:

- the number of publications that report HCX of patients with CHF in Germany;

- the thematic dimensions of HCX that are addressed;

- the range of publications, study designs and academic disciplines that deal with HCX in patients with CHF in Germany;

- the demographics of patients included in the primary studies;

- research activity across healthcare services;

- methods used to assess and evaluate HCX;

- the context of rurality and urbanity in studies of HCX.

\section{METHODS}

Details on the methodological procedure have been published elsewhere. ${ }^{10}$ Reporting complies with the Preferred Reporting Items for Systematic Reviews and Meta-Analyses extension for scoping reviews. ${ }^{15}$
Study selection, literature searches and screening process

Papers were eligible for inclusion in this review when they investigated adult patients with CHF, reported any outcome related to patient healthcare experience in the context of the German healthcare environment and were published between 2008 and 2018 in either English or German.

We conducted systematic literature searches in six electronic databases (CINAHL, MEDLINE, EMBASE, PsycINFO, PSYNDEX and the Cochrane Database of Systematic Reviews) in May 2018. A full search strategy for each database is provided in online supplementary appendix 1. Additionally, the following grey literature sources were searched: ProQuest and DART-Europe (January 2019), German National Library (April 2019), as well as the homepages of relevant German organisations (June 2019) (see online supplementary appendices 2,3). Experts were not personally contacted. Finally, we hand-searched reference lists of included publications. Searching indexes of key journals was not necessary, as the key journals identified by the review team were indexed in electronic databases. Database searches are detailed in the protocol.

Two reviewers (MD and EB) screened publications on a $\mathrm{Ti} / \mathrm{Ab}-\mathrm{level}$ and a full-text level (MD and JP) using Covidence software ${ }^{16}$ Conflicts were resolved by majority vote (MD, JP, JJP/FR).

\section{Data extraction and synthesis}

In accordance with the study protocol, data were extracted using a charting form developed by a multidisciplinary team and a patient representative (see online supplementary appendix 4) and entered in Microsoft Excel ${ }^{17}$ and MAXQDA ${ }^{18}$ software (MD). The following revisions were made to the protocolled data charting process. We extracted patient data on the living area (rural vs urban), employment status, educational background and state of mental health. Furthermore, since information from primary studies did not always fit into positive/negative/ bivalent experience categories, we extracted the main results of reported experiences verbatim, whenever possible.

Population and study characteristics were summarised quantitatively using both tabular formats and narrative description. We calculated means for metric data and frequencies for nominal data. Where extracted nominal data from primary studies did not allow obvious categorisation, we developed inductive categories (MD). Information on the professional background of the author(s), the journal and the study objective was used to allocate primary studies to research areas.

Healthcare services were reported in accordance with the European Health Observatory on Health Systems categorisation, ${ }^{19}$ which allows replication of this work in the healthcare contexts of other countries. We expanded these categories to include healthcare services that were rated important by the patient representative and 
mentioned in German clinical practice guidelines on $\mathrm{CHF}^{20}$

Following the approach of textual narrative synthesis, ${ }^{21}$ we grouped the included studies into subgroups according to the primary healthcare context under review. Within subgroups, we then produced commentaries for each individual study using direct quotes when possible.

Thematic dimensions of HCX were developed both, inductively and deductively using the 12 categories of patient-centred care published by Scholl $e t$ al. ${ }^{22}$ In order to identify research foci and research gaps regarding the range of HCX studied, deductive categories pragmatically served to 'set the scene'. Main results of the individual studies extracted included the authors' conclusions on HCX studied, reported findings on HCX derived from the results section or individual patient data in the format of quotes. All textual material was paraphrased and, if adequate, allocated to 12 deductive categories: essential characteristics of the clinician, clinician-patient relationship, patient as a unique person, biopsychosocial perspective, clinician-patient communication, integration of medical and non-medical care, teamwork and teambuilding, access to care, coordination and continuity of care, patient information, patient involvement in care, involvement of family and friends, patient empowerment, physical support and emotional support. ${ }^{21}$ As some textual material describing HCX did not fall into these categories, thematic codes further emerged from paraphrases during a second and third run through the material.

However, since reports of healthcare services varied, a subgroup synthesis was not performed. However, a frequency analysis of healthcare services and thematic dimensions of HCX was performed across all included publications and shown graphically.

\section{Patient and public involvement}

Unlike research on patient experiences derived from secondary data sources such as health claims data, this scoping review aims at mapping literature on HCX in patients with CHF from a genuine patients' perspective. Consequently, we partnered with a patient representative to specify outcome variables to be extracted and to refine the research question. This research is part of a wider research project that includes online dissemination of a healthcare report to lay audiences with the purpose of providing patients with accessible information to start engaging in future patient and public involvement initiatives.

\section{RESULTS}

Number of publications that report healthcare experiences of patients with chronic heart failure in Germany

Following deduplication, our search of electronic databases and grey literature resulted in 1489 references. Of these, 1384 references were excluded based on information in title and abstract, so that 105 references were assessed for eligibility based on their full texts. Of these, 87 were excluded, mainly because publications did not report patient experiences related to healthcare services, information was not provided by the patient or studies did not (separately) examine the German context. Figure 1 provides details of the screening process. Ultimately, 18 publications were included in this review.

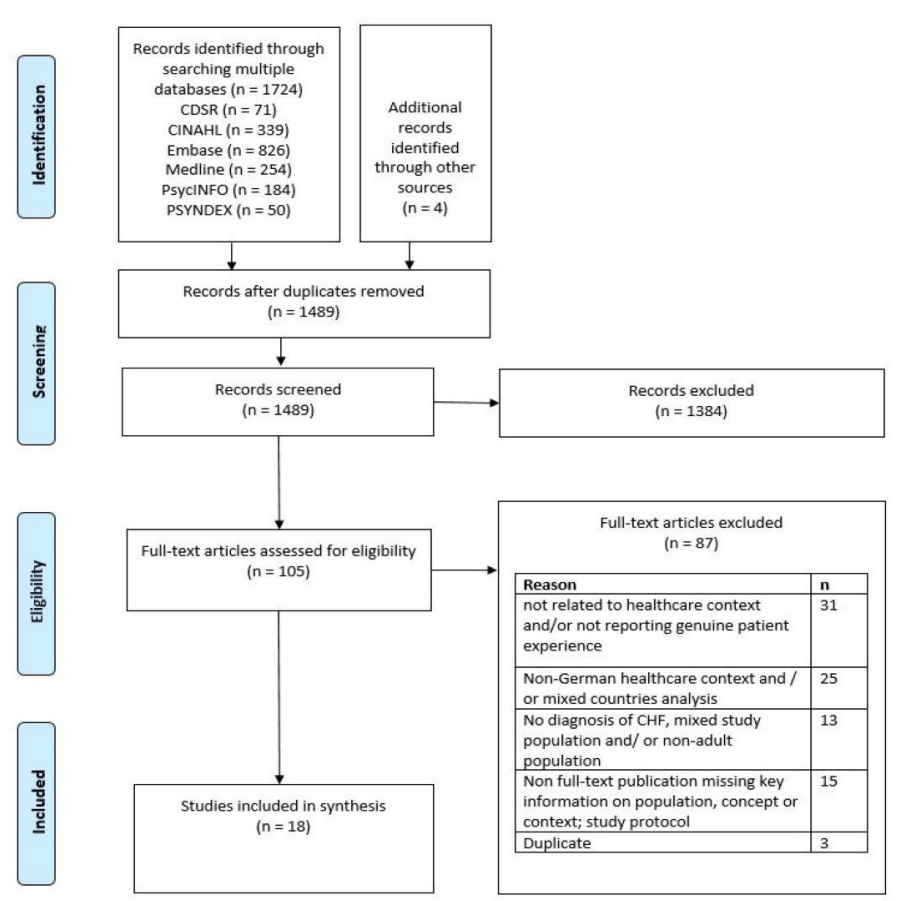

Figure 1 Study selection process. CHF, chronic heart failure. 


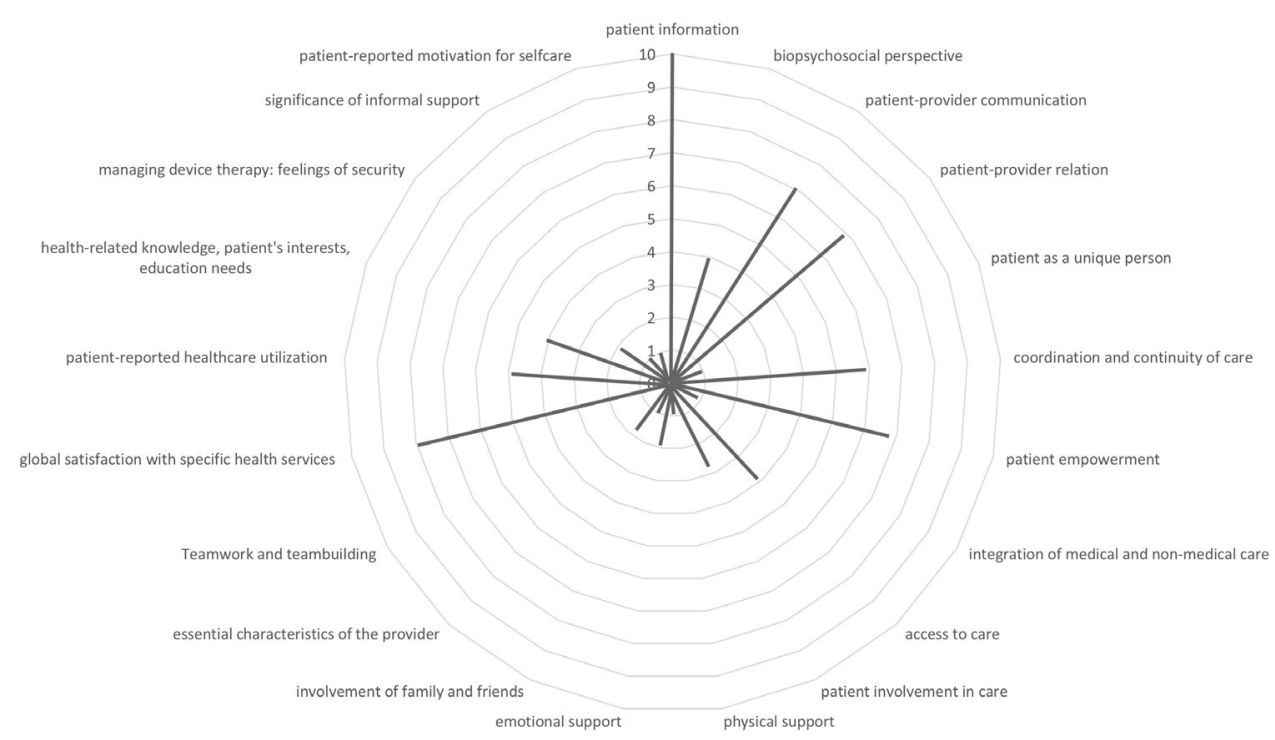

Figure 2 Number of times specific topics associated with healthcare experiences were described.

\section{Thematic dimensions of healthcare experience addressed}

The objectives of the studies varied (see online supplementary appendix 5). The majority of studies aimed to evaluate the relational aspects of how patients experience the interaction with providers. ${ }^{23-33}$ Some assessed, for instance, patients' utilisation of healthcare services, ${ }^{28}{ }^{3134-36}$ or the knowledge they gained by using certain services, ${ }^{23} 283738$ others collected less impersonal data.

Figure 2 depicts the number of times specific topics associated with HCX were described in the included studies. In the majority of cases, a single study addressed multiple topics. Over half of the studies reported experiences with patient information. ${ }^{23-26} 2831-333638$ These included topics such as the kind of information patients were interested in, ${ }^{23} 283338$ information seeking, ${ }^{23} 252831$ the emotional response to information ${ }^{26} 38$ and the quality of available information. ${ }^{23} 28$ Global satisfaction with providers, technical devices, therapies, financial support and educational programmes was the second most commonly reported topic in the studies. ${ }^{23} 262830323839$ Experiences of patient-provider communication, ${ }^{24} 252728313236$ relationships 23272830323336 as well as patient empowerment, ${ }^{24252730363839}$ were addressed in seven of the 18 studies, thus focusing on relational aspects of experiences, while coordination and continuity of care were reported in onethird of studies, ${ }^{26} 2829313236$ reflecting a focus on the organisational dimensions of HCX. Little research explored experiences with emotional or physical support, ${ }^{30} 3238$ the integration of medical and non-medical care, ${ }^{31}$ essential characteristics of the provider, ${ }^{27} 28$ patient perceptions of being a unique person ${ }^{27}$ and the involvement of family and friends. ${ }^{38}$ No study investigated experiences of patients with teamwork and teambuilding of healthcare providers.

The range of publications, study designs and academic discipline that deal with healthcare experiences in patients with CHF in Germany

The majority of studies were published in international and German academic peer-reviewed journals. ${ }^{23-27} 29-34$ 38-40
As we also performed grey literature searches, one in five references were doctoral theses. ${ }^{28}{ }^{35-37}$ The included references were published between 2008 and May 2018, with approximately half having been published within the past 3 years, possibly indicating a slight upward trend in publication activity. With regard to study design, most publications were designed as observational studies $(61 \%)^{23-26} 30313435373840$ followed by qualitative $(22 \%)^{27283233}$ and interventional studies (18\%). ${ }^{29} 3639 \mathrm{We}$ found no systematic reviews or non-clinical study designs, such as preference-based experiments. Accordingly, sample sizes varied substantially, ranging from 17 to 475 subjects per study. The majority of research stemmed from the health and medical sciences. Table 1 summarises the synthesised study characteristics, while online supplementary appendix 5 details study characteristics for each included reference. The studies' objectives varied substantially, reflecting diversity in study design and research area.

\section{Demographics of patients included in the primary studies}

Table 2 summarises synthesised findings of the study populations, while online supplementary appendix 6 details population characteristics for each included reference. Overall, 1868 patients were included in the primary studies of this review. One-third of patients were women. No study reported information on ethnicity or insurance status of patients, and fewer than half the studies reported data on relationship status, ${ }^{23-26} 28353739$ housing situation, ${ }^{24} 2628293134$ employment status 232531323539 and educational background. ${ }^{23-25} 313739$ Forty-four per cent of studies provided no data on comorbidities, risk factors and mental health. CHF was not further specified in the majority of studies.

\section{Research activity across healthcare services}

The evidence map in figure 3 shows the number of studies that reported HCX for different healthcare services and according to study design. It is of note that 
Table 1 Study characteristics of included studies

\begin{tabular}{|c|c|}
\hline Study characteristics $(n=18)$ & Number (\%) \\
\hline \multicolumn{2}{|l|}{ Year of publication } \\
\hline 2008-2012 & $5(28)$ \\
\hline 2013-2018 & $13(72)$ \\
\hline \multicolumn{2}{|l|}{ Type of publication } \\
\hline Journal article & $14(78)$ \\
\hline Doctoral thesis & $4(22)$ \\
\hline \multicolumn{2}{|l|}{ Study design } \\
\hline $\mathrm{RCT}$ & $3(17)$ \\
\hline Longitudinal study & $6(33)$ \\
\hline Cross-sectional study & $5(28)$ \\
\hline Qualitative study & $4(22)$ \\
\hline \multicolumn{2}{|l|}{ Research area* } \\
\hline Health services research & $8(44)$ \\
\hline Health education & $6(33)$ \\
\hline Psychosomatic medicine & $5(28)$ \\
\hline Geriatrics & $3(17)$ \\
\hline Family medicine & $3(17)$ \\
\hline Cardiac surgery & $3(17)$ \\
\hline Rehabilitation science & $3(17)$ \\
\hline Palliative medicine & $2(11)$ \\
\hline Pharmaceutical care & $2(11)$ \\
\hline Nursing & $1(6)$ \\
\hline Telemedicine & $1(6)$ \\
\hline \multicolumn{2}{|l|}{ Sample size } \\
\hline $10<\mathrm{n} \leq 25$ & $3(17)$ \\
\hline $25<\mathrm{n} \leq 100$ & $10(56)$ \\
\hline $100<\mathrm{n}<200$ & $3(17)$ \\
\hline $200<n<500$ & $2(11)$ \\
\hline \multicolumn{2}{|l|}{ Methods of assessment } \\
\hline Interviews & $5(28)$ \\
\hline Survey & $12(67)$ \\
\hline Group discussion & $1(6)$ \\
\hline \multicolumn{2}{|l|}{ Method of evaluation } \\
\hline Qualitative & $4(22)$ \\
\hline Quantitative & $12(67)$ \\
\hline Mixed & $2(11)$ \\
\hline
\end{tabular}

*Multiple selection possible.

$\mathrm{RCT}$, randomised controlled trial.

most studies could not be exclusively allocated to one healthcare context, and HCX was reported for multiple healthcare services within a single study. For example, 7 of 18 studies reported patient experiences with hospital care, ${ }^{24-26} 28323336$ of which one study was a randomised controlled trial (RCT) ${ }^{36}$ (from a total of 3 RCTs identified in this review, see figure 3). Overall, research activity was spread non-uniformly across healthcare
Table 2 Population characteristics of included studies

\begin{tabular}{lll}
$\begin{array}{l}\text { Population characteristics } \\
(\mathbf{n = 1 8 6 8 )}\end{array}$ & Outcome & $\begin{array}{l}\text { Reported } \\
\text { in } \mathbf{n} \\
\text { studies }\end{array}$ \\
\hline Mean age & 67 years & 16 \\
\hline Age range & $23-100$ years & 6 \\
\hline Sex (\% female) & $31 \%$ & 18 \\
\hline Ethnicity & - & 0 \\
\hline Insurance status & - & 0 \\
\hline Relationship status & & 8
\end{tabular}

Married, steady relationship $64 \%$

Single, divorced, widowed, $\quad 36 \%$ others

$\begin{array}{ll}\text { Housing situation } & 6 \\ \text { Living together } & 56 \% \\ \text { Living alone } & 23 \%\end{array}$

Assisted living, nursing home, 21\%

home care

\begin{tabular}{ll} 
Employment status & 6 \\
Employed & $27 \%$ \\
$\begin{array}{l}\text { Non-employed, retired, } \\
\text { others }\end{array}$ & $73 \%$ \\
\hline
\end{tabular}

Educational background

6

\begin{tabular}{lll}
$\begin{array}{l}\text { Minimum of } \mathbf{1 0} \text { school years } \\
\text { completed }\end{array}$ & $84 \%$ & \\
$\begin{array}{l}\text { Minimum of } \mathbf{1 3} \text { school years } \\
\text { completed }\end{array}$ & $16 \%$ & 15 \\
\hline $\begin{array}{l}\text { Severity of symptoms } \\
\text { NYHA I }\end{array}$ & $8 \%$ & \\
\hline NYHA II & $43 \%$ & \\
\hline NYHA III & $35 \%$ & 10 \\
\hline NYHA IV & $14 \%$ & \\
\hline $\begin{array}{l}\text { Comorbidities, risk factors, } \\
\text { state of mental health }\end{array}$ & Diverse \\
\hline $\begin{array}{l}\text { Type of heart failure } \\
\text { Aetiology }\end{array}$ & $\begin{array}{l}\text { Diverse } \\
\text { Pathophysiology }\end{array}$ & 3 \\
\hline Localisation & HFrEF, HFpEF & 6 \\
\hline Therapeutic characteristics & Giverse & 16 \\
\hline
\end{tabular}

HFpEF, heart failure with preserved ejection fraction; HFrEF, heart failure with reduced ejection fraction; NYHA, New York Heart Association.

services and study designs, indicating gaps and foci in research activity. Research was mostly undertaken to investigate HCX in ambulatory care settings (11/18 studies), ${ }^{24-26} 28$ 31-36 and predominantly based on qualitative $^{2832} 33$ and cross-sectional evidence. ${ }^{24-2635}$ Hospital care (7/18 studies), ${ }^{24-26} 28323336$ rehabilitation and 


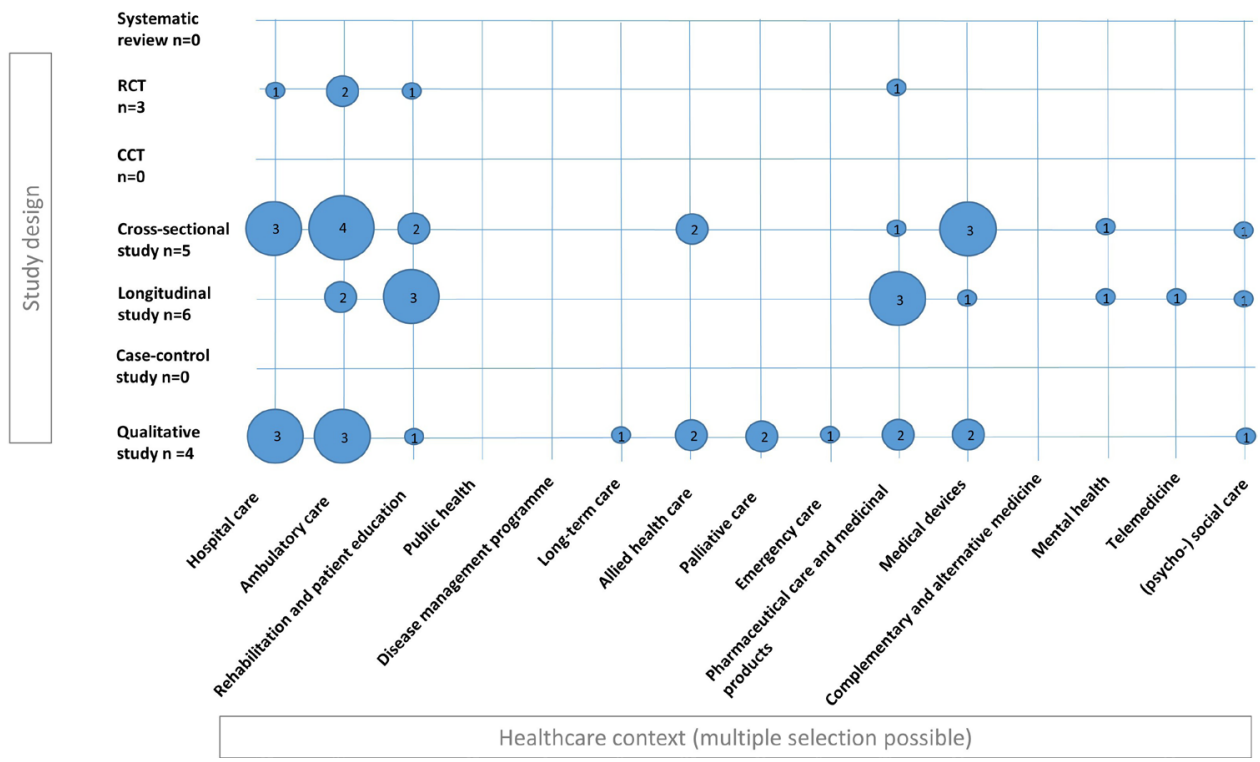

Figure 3 Number of publications according to healthcare context and study design. CCT, clinically controlled trial; RCT, randomised controlled trial.

patient education, ${ }^{23} 242631323839$ pharmaceutical care and medicinal products ${ }^{232531-333637}$ as well as medical devices ${ }^{25} 2630323340$ (the majority of which were investigated using observational studies) were less frequently investigated. Little research activity was observed for HCX with emergency care services, ${ }^{28}$ allied healthcare, ${ }^{26} 323335$ long-term care $(1 / 18$ studies $),{ }^{28}$ mental healthcare $(2 / 18$ studies), ${ }^{31} 35$ psychosocial healthcare (3/18 studies) ${ }^{26} 3132$ and telemedical care. ${ }^{30}$ No research investigated HCX with public health, disease management programmes and complementary and complementary medicine. Qualitative studies covered the widest range of healthcare services.

\section{Methods of assessing and evaluating healthcare experiences} Surprisingly, HCX was mostly evaluated quantitatively (10/18 studies) using questionnaires, ${ }^{23-25} 293035363840$ of which most were self-developed, as well as one interview. ${ }^{34}$ Only six studies used qualitative evaluation (interviews, ${ }^{27} 283132$ group discussion ${ }^{33}$ and questionnaire ${ }^{39}$ ). Two of 18 studies used mixed methods analysis. ${ }^{2637}$

\section{Rurality, urbanity and healthcare experiences}

It was not possible to determine the geographical location of reported HCX precisely, as the individual studies did not report patient residence codes. Only one study specifically provided information on whether reported HCX were assessed in rural, suburban or urban areas.

\section{DISCUSSION}

The aim of this study was to systematically review the past 10 years of research activity into the HCX of patients with CHF in Germany. We identified the following research foci. HCX were generally evaluated quantitatively $(60 \%)$. Most studies were observational $(60 \%)$. Contributions came from health services research (44\%), health education (33\%) and various medical disciplines. They primarily reported HCX in terms of patient information, global satisfaction, patient-provider relationships and communication. In descending order of frequency, HCX were reported for ambulatory care, hospital care, rehabilitation, pharmaceutical care and medicinal products, and the provision of medical devices. Overall, the heterogeneity of included studies' outcomes was substantial and permitted only relatively trivial levels of synthesis.

The investigation on patients' genuine views on healthcare services is an important goal in itself and must not exclusively be viewed as a means for healthcare systems to manage care more efficiently. ${ }^{11}$ We therefore excluded papers that reported HCX only from a provider perspective, or that analysed only health claims data. In this way, we assessed actual and (lived) experience and how they expressed itself emotionally and cognitively. Studies of this review examined experiences in terms of satisfaction, preferences, knowledge and desires rather than actual experience. Actual experience was understood to refer to quantitative information (eg, number of consultations with the doctor), relational experience (eg, interaction with provider perceived to need improvement) or organisational experience (eg, too little time to communicate with doctor).

This review maps the body of literature on HCX in both a population-specific and a country-specific context. This was necessary because system design and a particular (set of) condition(s) determine the healthcare realities that patients face. Results of this review may therefore not be transferable to different countries or patients with different conditions straightforwardly. The synthesis of qualitative evidence investigating experiences of patients with multimorbidity around the globe has found that the magnitude of perceived treatment burden is determined, among other things, by contextual factors such as the 
healthcare system and social environment. ${ }^{41}$ However, transferring this research to other care contexts can be performed by adjusting the search strategy.

A recently published scoping review reported ways to describe gaps and research priorities in health literature and found that research gaps mainly fell into three categories: missing information, inadequate information and insufficient information-all of which the present scoping review confirms. ${ }^{42}$

\section{Missing information}

Our results suggest that information on HCX in patients with CHF from systematic reviews and meta-research does not exist. The paucity of research in this field either suggests the phenomenon of HCX lacks the theoretical substantiation that is required before empirical research can be undertaken, or it may indicate that in Germany, the development of this particular research field is in its infancy.

\section{Inadequate information}

Surprisingly, despite increasing interest in patient experiences with quality of care, no study was carried out with the specific aim of assessing HCX. Individual studies tended rather to report HCX as an outcome that was not directly linked to their main objective, and was not mentioned in the title or abstract.

We found primary studies gave too little sociodemographic information (eg, insurance status, educational background or state of mental health) on the study population to provide the necessary context for a sound interpretation of HCX in the form of a full synthesis. For instance, patients with $\mathrm{CHF}$ are at considerable risk of cognitive decline and of having other mental health conditions, ${ }^{43}{ }^{44}$ which can shape HCX. It is therefore essential that primary studies provide adequate information on such factors in the future.

The healthcare services studied in the included publications were not always congruent with the list of care providers provided by the patient representative. Specifically, disease management programmes and heart failure nurses that patients rated as important have not been adequately reflected in research. This may indicate a gap in the coverage of certain important healthcare services.

\section{Insufficient information}

The importance of rurality and urbanity in influencing HCX could not be assessed, as primary studies lack sufficient data on where patients live. However, the increasing prevalence of $\mathrm{CHF}$ in the rural population suggests that investigations of HXC should take into account where the patient resides. ${ }^{45}$

Although 6 of the 18 studies were of a longitudinal nature, they provided little information on changes in HXC throughout the patient's lifetime and throughout the course of the illness. According to the theoretical framework of complex adaptive chronic care, ${ }^{46}$ patients typically experience periods of stability, self-management and routine care combined with acute exacerbations, as well as complex and unstable phases that often demand inpatient health services. Hence, patients journey through different stages of their disease and through diverse healthcare settings along their chronic illness trajectories.

Traditionally, HCX assessment has been extensively used in inpatient sectors, but patient-reported measures of HCX are increasingly being developed for multiple healthcare settings or specific populations. ${ }^{47} 48$ Such patient-reported outcome measures may be used to develop innovative reimbursement models or metrics to assess the performance of healthcare systems. ${ }^{49}$ Against the background of such diverse opportunities for the application of HCX, we must consider the concept of patient experience as a source of information that can enable us to increase quality of care rather than as a tool to measure cost efficiency in competing healthcare providers.

This review also emphasises the dominant role of the application of quantitative methods in exploring patient experiences. However, the application of qualitative research (synthesis) may help explore and conceptually carve out phenomena such as patient experience with healthcare. Furthermore, HCX can be measured in many different ways and make use of varying levels of generalisability and information. ${ }^{50}$ Nonetheless, in this review, we found that the methods used to assess HCX were mainly interviews, surveys and group discussions, indicating that the use of other methodologies may result in considerable gains.

\section{LIMITATIONS}

Overall, the considerable heterogeneity of the included studies' outcomes only permitted relatively trivial levels of synthesis. Moreover, data extraction was performed by a single researcher, so the generation of codes and allocation of data to inductive categories lacks triangulation and may therefore reflect the single researcher's perspective.

In retrospect, as burden of treatment is increasingly being investigated and is closely linked to the broad range of topics that comprise HCX, we may have missed some publications by not including this term in the search strategy.

Although a patient representative was involved in defining relevant extraction categories, we think that involving patients in the review process further would offer valuable insights into the identification of patientrelevant research gaps. The scoping review methodology may help in identifying these gaps.

Importantly, study quality of the included publications was not assessed. The outcomes of HCX reported herein may therefore be subject to methodological problems in the conduct of the primary studies included in this review, such as small sample sizes or bias introduced by interviewer effects. Appraising study quality would be a necessary step if full evidence synthesis was the aim. 


\section{CONCLUSION}

Overall, research activity is characterised by substantial heterogeneity in formulated study aims and the reported outcomes of healthcare experience. Consequently, an in-depth thematic synthesis of the results is not indicated at this stage. However, more and precise primary research may provide information from (qualitative) systematic reviews that is focused on specific thematic dimensions of healthcare experience or a particular healthcare setting, and this may support the development of an evidencebased understanding of patient experiences with CHFspecific healthcare in Germany.

Research into the HCX of patients with CHF in Germany is characterised by missing, insufficient and inadequate information. Replication of this work with a focus on other countries' healthcare systems will help systematically investigate the HCX of patients with CHF. In Germany, future research should specifically address the following:

- Scientific analysis of patients' HCX based on data from digital sources such as consumer platforms, social media and patient's blogs, as these data sources may deliver insightful information to complement that gained using the traditional assessment methods that have been used so far.

- Investigation of HCX in understudied healthcare contexts to improve the patient experience holistically and not exclusively for individual providers and services.

- More evidence from qualitative studies for an in-depth understanding of the concept of HCX.

- If possible, sociodemographic patient information should be reported in detail in primary studies, as it provides an important context for the interpretation of HCX.

- Evidence from longitudinal studies should assess patient opinions at multiple time points along the disease trajectory, as experience is likely to shift in line with changing symptoms.

- Evidence of the HCX of female subjects, as they were not equally represented in the studies under review.

Acknowledgements The authors would like to thank Eva Breitinger for co-screening titles and abstracts as well as Phillip Elliott for proof-reading the manuscript.

Contributors JJP, AS and FMG conceptualised this work. KJ, TS, AS, JJP, FR and MD developed the search strategy. JJP, MD, FR and JP were involved in screening and selection processes. MD extracted data and analysed the extracted results together with CG. All authors critically revised and approved the manuscript.

Funding This research was supported by the Robert Bosch Foundation.

Disclaimer The funders were not involved in the conception, conduct or interpretation of this study.

Competing interests JJP is a co-investigator in the PANORA study ('Prevalence of anticyclic citrullinated peptide (CCP) positivity in patients with new non-specific onset of musculoskeletal symptoms, possibly related to early rheumatoid arthritis in general practices in Germany'), which is being conducted by the Fraunhofer Institute and financed by Bristol-Meyer Squibb. She is employed by the Institute of General Practice of Goethe University Frankfurt and has never personally received financial remuneration from a pharmaceutical company. The other authors report no conflict of interest.
Patient consent for publication Not required.

Provenance and peer review Not commissioned; externally peer reviewed.

Data availability statement All data relevant to the study are included in the article or uploaded as supplementary information. All data relevant to the study are included in the article, the protocol or uploaded as supplementary information.

Open access This is an open access article distributed in accordance with the Creative Commons Attribution Non Commercial (CC BY-NC 4.0) license, which permits others to distribute, remix, adapt, build upon this work non-commercially, and license their derivative works on different terms, provided the original work is properly cited, appropriate credit is given, any changes made indicated, and the use is non-commercial. See: http://creativecommons.org/licenses/by-nc/4.0/.

ORCID iD

Andrea Siebenhofer http://orcid.org/0000-0002-6980-2103

\section{REFERENCES}

1 Gallacher K, May CR, Montori VM, et al. Understanding patients' experiences of treatment burden in chronic heart failure using normalization process theory. Ann Fam Med 2011;9:235-43.

2 Shippee ND, Shah ND, May CR, et al. Cumulative complexity: a functional, patient-centered model of patient complexity can improve research and practice. J Clin Epidemiol 2012;65:1041-51.

3 May CR, Mair F, Finch T, et al. Development of a theory of implementation and integration: normalization process theory. Implement Sci 2009;4:29.

4 Leppin AL, Montori VM, Gionfriddo MR. Minimally disruptive medicine: a pragmatically comprehensive model for delivering care to patients with multiple chronic conditions. Healthcare 2015;3:50-63.

5 Tran V-T, Barnes C, Montori VM, et al. Taxonomy of the burden of treatment: a multi-country web-based qualitative study of patients with chronic conditions. BMC Med 2015;13:115.

6 Sav A, King MA, Whitty JA, et al. Burden of treatment for chronic illness: a concept analysis and review of the literature. Health Expect 2015;18:312-24.

7 Demain S, Gonçalves A-C, Areia C, et al. Living with, managing and minimising treatment burden in long term conditions: a systematic review of qualitative research. PLoS One 2015;10:e0125457.

8 Herber OR, Kastaun S, Wilm S, et al. From qualitative meta-summary to qualitative meta-synthesis: introducing a new Situation-Specific theory of barriers and facilitators for self-care in patients with heart failure. Qual Health Res 2019;29:96-106.

9 Sav A, Salehi A, Mair FS, et al. Measuring the burden of treatment for chronic disease: implications of a scoping review of the literature. BMC Med Res Methodol 2017;17:141.

10 Dieckelmann M, Reinhardt F, Jeitler K, et al. Chronic heart failure patients' experiences of German healthcare services: a protocol for a scoping review. BMJ Open 2019;9:e025685.

11 Trevena $\mathrm{L}$. Minimally disruptive medicine for patients with complex multimorbidity. Aust J Gen Pract 2018;47:175-9.

12 Arksey H, O'Malley L. Scoping studies: towards a methodological framework. Int J Soc Res Methodol 2005;8:19-32.

13 Levac D, Colquhoun H, O'Brien KK. Scoping studies: advancing the methodology. Implement Sci 2010;5:69.

14 Munn Z, Peters MDJ, Stern C, et al. Systematic review or scoping review? guidance for authors when choosing between a systematic or scoping review approach. BMC Med Res Methodol 2018;18:143.

15 Tricco AC, Lillie E, Zarin W, et al. PRISMA extension for scoping reviews (PRISMA-ScR): checklist and explanation. Ann Intern Med 2018;169:467-73.

16 Covidence. Covidence systematic review software. Melbourne, Australia: Veritas Health Innovation, 2020.

17 Microsoft Corporation. Microsoft excel, 2018.

18 MAXQDA. VERBI software 2017. Berlin, Germany, 2018.

19 Busse R, Blümel M. Germany: health system review. Health Syst Transit 2014;16:179-236.

20 Federal Medical Association, National Association of Statutory Health Insurance Physicians, Working Group of Scientific Medical Societies. Nationale versorgungsLeitlinie Chronische Herzinsuffizienz - Langfassung (3 Auflage) [German clinical practice guidelines for chronic heart failure], 2019.

21 Lucas PJ, Baird J, Arai L, et al. Worked examples of alternative methods for the synthesis of qualitative and quantitative research in systematic reviews. BMC Med Res Methodol 2007;7:4.

22 Scholl I, Zill JM, Härter M, et al. An integrative model of patientcenteredness - a systematic review and concept analysis. PLoS One 2014;9:e107828. 
23 Meng K, Schubmann R, Hohoff M, et al. Schulungsbedürfnis von Patienten mit Herzinsuffizienz in der medizinischen Anschlussrehabilitation [CHF patients' needs for health education in rehabilitation following hospital stays]. Praxis Klinische Verhaltensmedizin und Rehabilitation 2009;83:67-77.

24 Köberich S. Fostering self-care behaviours through symptom diary use? an exploratory, cross-sectional study about the use of and attitude towards a symptom diary of patients with heart failure. $J$ Res Nurs 2016;21:530-41.

25 Dahrmann B, Sindermann J, Geldmacher T, et al. Lebensqualität und psychisches Befinden von Patienten mit schwerer Herzinsuffizienz mit und ohne apparative Unterstützung der Funktion des linken Ventrikels-eine Querschnittsstudie [Quality of life and mental health of patients with severe heart failure with or without technical support for the left cardiac ventricle -a crosssectional study]. Zeitschrift für Psychosomatische Medizin und Psychotherapie 2017;4:388-404.

26 Berg T, Tewarie L, Moza A, et al. Anforderungen an die ambulante Versorgung nach Implantation eines ventrikulären Herzunterstützungssystems [Requirements for outpatient care after implantation of a ventricular assist device]: Sichtweise von Patienten und Angehörigen. Herz 2017;44:257-64.

27 Werdecker L, Kujawa M, Schneider N, et al. Advance care planning: Eine qualitative Untersuchung zur Patientenperspektive bei fortgeschrittener Herzinsuffizienz [Advance care planning: a qualitative investigation on patients' perspectives with advanced heart failure]. Z Gerontol Geriatr 2019;52:157-63.

28 Klindtworth K. Versorgungssituation und Bedürfnisse am Lebensende [Health care needs at the end of life]: Perspektiven von älteren Patienten und Patientinnen mit schwerer Herzinsuffizienz und ihren Angehörigen, 2015.

29 Peters-Klimm F, Campbell S, Hermann K, et al. Case management for patients with chronic systolic heart failure in primary care: the HICMan exploratory randomised controlled trial. Trials 2010;11:56.

30 Müller A, Goette A, Perings C, et al. Potential role of telemedical service centers in managing remote monitoring data transmitted daily by cardiac implantable electronic devices: results of the early detection of cardiovascular events in device patients with heart failure (detecT-Pilot) study. Telemed J E Health 2013;19:460-6.

31 Lossnitzer N, Herzog W, Schultz JH, et al. A patient-centered perspective of treating depressive symptoms in chronic heart failure: what do patients prefer? Patient Educ Couns 2015;98:783-7.

32 Baudendistel I, Noest S, Peters-Klimm F, et al. Bridging the gap between patient needs and quality indicators: a qualitative study with chronic heart failure patients. Patient Prefer Adherence 2015;9:1397-405.

33 Herzberg $\mathrm{H}$, Bernateck K, Welti F, et al. Patientenbeteiligung bei der Entwicklung von Qualitätsindikatoren am Beispiel der Nationalen VersorgungsLeitlinie Chronische Herzinsuffizienz [Patient Participation in Development of Quality Indicators using the Example of National Disease Management Guidelines for Chronic Heart Failure]: Eine qualitative Analyse kollektiver Sichtweisen. Gesundheitswesen 2016;78:373-7.

34 Scherer M, Himmel W, Kochen MM, et al. Psychosocial determinants for frequent primary health care utilisation in patients with heart failure. Psychosoc Med 2008;5:Doc02.
35 Naumann K. Herzinsuffizienz: Einfluss auf die sozioökonomische Situation des Patienten [Heart failure: impact on the patient's socioeconomic situation], 2014.

36 Knoll A. Apotheken-basierte Maßnahmen zur Verbesserung der Einnahmetreue bei älteren Patienten mit chronischer Herzinsuffizienz [Pharmacy-based programs to improve medication adherence in elderly patients with chronic heart failure], 2014.

37 Rohlehr F. Medikamenten-assoziiertes Wissen und Adhärenz bei Patienten mit dekompensierter Herzinsuffizienz bei Aufnahme und Entlassung aus dem Krankenhaus [Medication-associated knowledge and adherence in patients with decompensated heart failure on admission and discharge from the hospital], 2017.

38 Muschalla B, Glatz J, Karger G. Kardiologische Rehabilitation mit strukturierter Schulung bei Herzinsuffizienz [Cardiac rehabilitation with a structured education programme for patients with chronic heart failure]: Akzeptanz bei Patienten und Veränderungen in Krankheitswissen und Wohlbefinden. Rehabilitation 2011;50:103-10.

39 Meng K, Musekamp G, Schuler M, et al. The impact of a selfmanagement patient education program for patients with chronic heart failure undergoing inpatient cardiac rehabilitation. Patient Educ Couns 2016;99:1190-7.

40 Meyer AL, Kugler C, Malehsa D, et al. Patient satisfaction with the external equipment of implantable left ventricular assist devices. Artif Organs 2010;34:721-5.

41 Rosbach M, Andersen JS. Patient-experienced burden of treatment in patients with multimorbidity - a systematic review of qualitative data. PLoS One 2017;12:e0179916.

42 Nyanchoka L, Tudur-Smith C, Thu VN, et al. A scoping review describes methods used to identify, prioritize and display gaps in health research. J Clin Epidemiol 2019;109:99-110.

43 Angermann CE, Ertl G, Depression EG. Depression, anxiety, and cognitive impairment: comorbid mental health disorders in heart failure. Curr Heart Fail Rep 2018;15:398-410.

44 Hammond CA, Blades NJ, Chaudhry SI, et al. Long-term cognitive decline after newly diagnosed heart failure: longitudinal analysis in the CHS (cardiovascular health study). Circ Heart Fail 2018;11:e004476.

45 Holstiege J, Akmatov MK, Steffen A, et al. Prävalenz der Herzinsuffizienz [Prevalence of heart failure]: bundesweite Trends, regionale Variationen und häufige Komorbiditäten: Zentralinstitut für die kassenärztliche Versorgung in Deutschland (Zi), 2018.

46 Martin C, Sturmberg J. Complex adaptive chronic care. J Eval Clin Pract 2009;15:571-7.

47 Eton DT, Yost KJ, Lai J-S, et al. Development and validation of the patient experience with treatment and self-management (PETS): a patient-reported measure of treatment burden. Qual Life Res 2017;26:489-503.

48 Gallacher KI, Quinn T, Kidd L, et al. Systematic review of patientreported measures of treatment burden in stroke. BMJ Open 2019;9:e029258

49 Braithwaite J, Hibbert P, Blakely B, et al. Health system frameworks and performance indicators in eight countries: a comparative international analysis. SAGE Open Med 2017;5:205031211668651.

50 The Health Foundation. Measuring patient experience: evidence scan, 2013. Available: https://www.health.org.uk/publication/ measuring-patient-experience 